\title{
Educação popular em saúde com o povo indígena Xukuru do Ororubá*
}

Juliana Santos Siebra Brito ${ }^{1}$

Paulette Cavalcanti de Albuquerque ${ }^{2}$ Edson Hely Silva ${ }^{3}$

\section{Por que fazer educação popular em saúde (EPS) com o povo Xukuru do Ororubá?}

A história e o desenvolvimento dos Xukuru do Ororubá foram motivo de várias pesquisas, tanto das Ciências Sociais como da Saúde, e, a partir de alguns estudos realizados com o povo, pelos pesquisadores do Centro de Pesquisas Aggeu Magalhães (CPqAM), instituição da Fundação Oswaldo Cruz (Fiocruz) em Pernambuco, observou-se a necessidade de uma qualificação no trabalho educativo dos agentes indígenas de saúde (AIS) e agentes indígenas de saneamento (AISAN). Com isto, desenvolveu-se uma proposta fundamentada em ofertar formas alternativas de fazer educação e em sugerir a reflexão das estruturas de produção de cuidado em saúde e de conhecimento, inclusive buscando uma análise do papel do Sistema Único de Saúde (SUS) na estrutura do Subsistema de Saúde Indígena. O desenvolvimento do aspecto educativo do trabalho dos AIS e AISAN seria diferenciado na medida em que estimulasse a coprodução de sujeitos autônomos, partindo de um fazer/ser solidário, baseado na metodologia da Educação Popular.

\section{Um breve relato sobre a história dos guerreiros do Ororubá e a organização sociopolítica e de saúde do povo}

Em 1654, com a autorização da distribuição de sesmarias, no agreste pernambucano, aos senhores de engenho, os indígenas Xukuru, da Serra do Ororubá, foram obrigados a trabalhar nas fazendas, plantações e, posteriormente, nas indústrias que foram abertas. Em pequenas porções de terra, moravam e plantavam o que podiam para seu próprio consumo (Silva, 2007). Segundo relato de um dos indígenas: "a gente trabalhava na terra deles, mas tinha a nossa roça, que a gente plantava milho pra comer, quando estava perto de colher, os fazendeiros soltavam o gado pra comer o nosso milho". A atitude opressora em relação aos Xukuru pode ser evidenciada em um relatório oficial escrito em 1944, por um sertanista do Serviço de Proteção ao Índio, ao falar sobre o incômodo dos fazendeiros da região com as práticas culturais do povo, culminando com uma denúncia à polícia local e a proibição de rituais religiosos e de curas tradicionais (Silva, 2007).
Elaborado com base em Brito( 2010); e na sistematização das informações e experiências promovidas pela pesquisa "Educação popular em saúde com o povo indígena Xukuru do Ororubá", financiada pela FACEPE, aprovada pelo CONEP/CNS/MS, com registro no $C A A E$ e no CEP/CPqAM/FIOCRUZ.

1-2 Núcleo de Estudos em Saúde Coletiva, Centro de Pesquisas Aggeu Magalhães, Fundação Oswaldo Cruz. Av. Professor Moraes Rego, $s / n$, Campus da Universidade Federal de Pernambuco, Cidade Universitária. Recife, $\mathrm{PE}$, Brasil. 50.670-420. julianasiebra@hotmail.com.

${ }^{3}$ Colégio de Aplicação, Centro de Educação, Universidade Federal de Pernambuco. 
EDUCAÇÃO POPULAR EM SAÚDE COM O POVO INDÍGENA ...

A luta pela retomada do território pode ser observada em vários episódios da história do povo, mas foi, no final da década de 1980, caracterizada pelo início da redemocratização, que as lutas pela terra tornaram-se mais acirradas entre diversos povos indígenas e fazendeiros. As garantias legais, baseadas na Constituição de 1988, e o empenho do cacique Francisco de Assis Araújo, o Xicão, nas mobilizações da Assembleia Nacional Constituinte, foram fatos que fortaleceram a luta indígena Xukuru. Sob sua liderança, iniciou o processo de mobilizações pela demarcação territorial, provocando fúria em muitos fazendeiros. Em 1998, o cacique foi assassinado, tendo a Polícia Federal comprovado que a motivação para o crime foi a tentativa de enfraquecer o movimento pela retomada das terras indígenas. Posteriormente, outras lideranças, como "Xico Quelé", também foram mortas, entretanto, tais violências não impediram a conquista da demarcação da terra indígena Xukuru, em 2001.

Como resultado da organização política construída no período de Xicão, tem-se a constituição dos Conselhos de Lideranças, de professores(as) Xukuru e o de Saúde (Piani, 2009). O momento de grande encontro e tomada de decisões ocorre anualmente, na Assembleia do Povo Xukuru, que reúne, ao menos, dez representantes das 24 aldeias.

Constituindo a rede de saúde, os territórios indígenas contam com os polos-base como instância de atendimento pela equipe multidisciplinar. A população Xukuru é coberta com um polo-base, que atende a grande maioria dos Xukuru, havendo postos de saúde para suporte das equipes multiprofissionais, distribuídos no território. Neste âmbito, o agente indígena de saúde, profissional obrigatoriamente de origem indígena local, compõe a equipe do polo-base, sendo um personagem-chave para a compreensão das práticas tradicionais do povo pelos trabalhadores não indígenas, o que aproximaria a atuação técnica padronizada do que faz e pensa o povo em relação à sua saúde.

\section{A prática do agente indígena de saúde: educativa ou prescritiva (e técnico-burocrática)?}

Os AIS devem ser indígenas contratados através de um processo seletivo, que considere critérios como: ser residente na aldeia de atuação, ter aptidão para o trabalho em saúde e bom relacionamento com a comunidade. Algumas atribuições do AIS também foram definidas pela Funasa e, entre trabalhos técnicos e burocráticos, são descritas também funções políticas, com a atuação frente a problemas ambientais e sociais (Fundação Nacional de Saúde, 2004).

As competências do AIS não divergem muito das do agente comunitário de saúde (ACS). Entretanto, apesar da semelhança de atribuições, os AIS Xukuru parecem não se identificar, enquanto profissionais, com os ACS de Pesqueira, município que compõe o território indígena - o que influencia na falta de participação daqueles em movimentos reivindicatórios de classe, como os realizados por sindicatos e associações.

Ao basear seu trabalho na promoção da saúde, o agente indígena de saúde necessita de autonomia e capacidade de compreender a influência do meio sociopolítico na saúde das pessoas. Ao exercer seu papel político, deve desenvolver uma dimensão do saber, dentro de sua competência profissional, que seria o "saber-ser", reconhecido como uma produção de si mesmo que se expressa pela capacidade de crítica, reflexão e mudança ativa de sua subjetividade e práticas (Brasil, 2010). Entretanto, apesar do acúmulo do poder político, os AIS acabam priorizando o papel técnico e burocrático.

Habermas, em referência à Teoria do Agir Comunicativo, enfatiza a necessidade de, através de relações dialógicas, produzirem-se cenários políticos que favoreçam a emancipação humana, inclusive na vida do trabalho (Cardoso, 2004). O agir comunicativo do AIS, muitas vezes, é degradado, sendo um espelho da prática vivenciada pelas equipes de saúde da família. A clínica destes profissionais distorcese quando reduzida à prescrição de condutas e medicamentos, sendo que esse modo de trabalho não dialoga com as práticas tradicionais indígenas. 


\section{Educação popular em saúde: as referências teóricas e a prática para projeto com o povo Xukuru}

Em janeiro de 1982, Paulo Freire, reunido num círculo de cultura, em São Paulo, proferiu um pensamento mencionando que a superação da postura "de querer libertar dominando" acontecerá quando entendermos que "não estamos sozinhos no mundo", e que o processo de libertação não é uma obra de uma só pessoa ou grupo, mas "de todos nós". De acordo com Paulo Freire, cinco princípios são fundamentais para nos assumirmos como autores, e não reféns da história: "saber ouvir, desmontar a visão mágica dos poderes instituídos, aprender/estar com o outro, reconhecer a ingenuidade dos educandos (as) e viver pacientemente impaciente" (Ceccim, 2007, p.35).

Vasconcelos (2007) revela uma compreensão das origens da educação popular com ponto de partida em movimentos de pensadores latino-americanos, constituídos na década de 1950, em busca de uma aproximação com o mundo popular, onde Paulo Freire foi o primeiro a sistematizar teoricamente as experiências acumuladas, no livro "Pedagogia do Oprimido", escrito em 1966. Ainda refere que o conhecimento adquirido mediante relações sociais é a matéria-prima da educação popular. Entretanto, estes saberes, fazendo-se analogia à arte, não devem ser trabalhados individualmente pelos educadores, como uma obra de arte nas mãos do artesão solitário, acreditando-se que o pensamento e vontade populares estão totalmente vulneráveis às opiniões do educador, mas, antes, devem ser uma obra onde todos contribuem, todos colocam as mãos e dão o seu toque pessoal.

A valorização do diálogo - significando este o saber ouvir e poder falar, assim como o respeito pelo conhecimento, emoções e experiências do povo - é uma diretriz básica da educação popular. $O$ sentimento que a orienta talvez seja a busca da solução dos problemas da sociedade, mas ultrapassa a questão ética, abrangendo o desejo, a personalidade humana, a constituição de cada ser. Na verdade, a compaixão, a solidariedade e o respeito pelo outro seriam os sentimentos que direcionariam todas as ações.

De acordo com Albuquerque (2003), a Educação Popular em Saúde teve sua origem na década de 1970, com as experiências de profissionais de saúde, que, através das Comunidades Eclesiais de Base, atuavam no meio popular, no contexto da retomada dos movimentos sociais de luta contra a ditadura.

Em Recife, no ano de 2001, a Coordenação de Educação em Saúde, vinculada à Secretaria Municipal de Saúde, definiu a educação popular como eixo direcionador teórico e metodológico das ações educativas (Recife, 2001b apud Albuquerque, 2003). Entretanto, houve dificuldade em reconstruir as práticas de saúde na atenção primária com profissionais que não tinham a educação popular como opção política. Paulo Freire afirmava que "a neutralidade frente ao mundo, frente ao histórico, frente aos valores, reflete apenas o medo que se tem de revelar o compromisso" (Freire, 2001, p.19). Segundo o pedagogo, não existe neutralidade, porque quem se diz neutro, na verdade, assume uma postura de compromisso com o poder vigente, com seus interesses e com os do grupo ao qual pertence.

A experiência de implantação da educação popular em saúde na atenção primária do Recife serviu como referência prática para o projeto com o povo Xukuru. Ambas as experiências se iniciaram com a identificação de problemas e potencialidades das comunidades e com o planejamento das ações educativas necessárias, assim como tiveram, na figura do agente de saúde, uma peça importante para o estímulo ao envolvimento popular na promoção de saúde. O ACS ou AIS, nestes casos, era estimulado a conduzir grupos em sua comunidade para discussão de problemas sociais e de saúde, constituindo-se um personagem essencial na orientação política e educativa da população.

\section{As práticas de educação popular em saúde com o povo Xukuru}

O projeto de educação popular, atuando a partir da inevitável participação e envolvimento dos pesquisadores com os demais participantes, deve buscar metodologias de pesquisa que combinem com 
EDUCAÇÃO POPULAR EM SAÚDE COM O POVO INDÍGENA ...

esta forma de pensar. Assim sendo, o projeto de educação popular com os Xukuru recorreu à pesquisaação, como instrumento metodológico, por esta ser realizada em estreita associação com uma ação ou com a resolução de um problema coletivo, havendo o envolvimento dos pesquisadores, de modo cooperativo ou participativo. Ainda, objetiva proporcionar, aos participantes do estudo, a possibilidade de discutirem um problema real e formularem soluções conjuntamente, partindo-se de um diagnóstico situacional, onde pesquisador e participante têm direito à expressão (Thiollent, 1998).

A prática da EPS com o povo Xukuru aconteceu a partir de espaços de diálogo e criação. A sistematização deu-se por meio de relatórios das atividades, diário de campo e registros das falas, escritos a partir das rodas de conversa e oficinas. Os encontros eram realizados nas sextas-feiras e sábados, uma ou duas vezes por mês, na escola indígena "Natureza Sagrada". Os interessados identificados na fase exploratória foram: algumas lideranças Xukuru, AIS/AISAN e os pesquisadores do CPqAM. Após acordo, com líderes do povo, das ações que seriam realizadas, prosseguiu-se com o diagnóstico participativo e com o planejamento das atividades.

\section{Seminário para diagnóstico inicial e planejamento das ações}

Em dezembro de 2008, na Aldeia de São José, ocorreu a primeira oficina, com pesquisadores e participantes voluntários do projeto. Estavam presentes: AIS, AISAN, lideranças do povo, estudantes e pesquisadores do CPqAM. Por meio de um diagnóstico participativo, foram elencados os principais problemas observados pelos participantes, que poderiam ser trabalhados em ação e diálogo sob o olhar da educação popular. De acordo com Stotz, David e Bornstein (2007), o diagnóstico participativo não serve apenas para identificar problemas, mas, também, para estabelecer prioridades de ação e pactuar estratégias coletivas de intervenção sobre a realidade.

Dentre as dificuldades enfatizadas pelos Xukuru, nesta roda de conversa, estavam:

a) A entrega de cestas básicas, como um benefício prestado a famílias com crianças abaixo do peso ideal e desnutridas. De acordo com relatos, alguns pais chegavam a subnutrir a criança para manterem o recebimento da cesta. Segundo um indígena: "Nós temos terra, água e não queremos cesta básica. Devemos conscientizar a mãe desse problema";

b) O excessivo consumo de álcool pela população, que foi expresso em falas como: "O álcool atrapalha a vida das pessoas", "O álcool é um problema, acho que um dos maiores dentro da nossa comunidade" e "Perguntei um dia pra uma criança o que ela queria ser quando crescer, e ela disse: 'Eu quero beber cachaça'";

c) A fragilidade do perfil educativo dos AIS, com rotina estabelecida de entrega de medicamentos e de marcação de consultas;

d) A falta de reconhecimento legal dos AIS como classe profissional, fato que contribuiu para a exclusão destes trabalhadores do processo de efetivação, que contemplou apenas os agentes comunitários de saúde vinculados à Prefeitura de Pesqueira.

Neste momento, foram propostas estratégias de avanço, com a constituição de grupos pelos ciclos da vida nas aldeias, orientados por duplas de AIS/AISAN. Reforçou-se a importância de o próprio agente escolher o ciclo da vida que despertasse o seu interesse, iniciando o projeto nas aldeias onde as pessoas demonstrassem disponibilidade. Assim, com o planejamento, foram definidos: os AIS/AISAN participantes, as aldeias, as redes de ajuda e o público-alvo. Os agentes identificaram adolescentes e jovens como a faixa etária com maior aceitação e disponibilidade para trabalhar com os problemas elencados. Desta forma, sugeriu-se que o processo educativo tivesse início com esta população, com o objetivo de prepará-la para a educação em saúde.

Este seminário foi encerrado com a definição de tarefas a serem realizadas pelos participantes Xukuru: identificar adolescentes e jovens voluntários, selecionar os temas a serem discutidos e realizar um encontro entre AIS e AISAN, para compartilhar dificuldades e potencialidades relacionadas ao desenvolvimento do projeto. 


\section{Encontros para Educação Popular em Saúde}

Os encontros realizados tinham como objetivo formar AIS/AISAN para a constituição de grupos de adolescentes e jovens educadores em saúde. Por meio de oficinas sobre a história das políticas públicas de saúde, desenvolvimento do SUS, cidadania e formação de grupos, buscou-se dar subsídios teóricos para uma melhor compreensão do papel político dos agentes indígenas.

No segundo encontro, foi realizada uma oficina com o tema "Como formar grupos". Este momento caracterizou-se pela descontinuidade da presença de alguns AIS e AISAN e pela dificuldade, relatada, em mobilizar os Xukuru. Os agentes expuseram algumas limitações para o desenvolvimento do projeto, como o descomprometimento de colegas de trabalho e o pouco entendimento sobre os assuntos de saúde. Este momento teve como encaminhamento duas reuniões: uma entre AIS e AISAN, para formular a programação dos grupos locais, e outra entre os agentes indígenas, adolescentes e jovens que comporiam os grupos nas aldeias.

No terceiro encontro do projeto, a proposta incluía o diálogo, entre pesquisadores e demais participantes, sobre cidadania. Entretanto, no primeiro dia deste momento, vários AIS/AISAN estavam ausentes - falta justificada, por um dos agentes, pela dificuldade em constituir os grupos nas aldeias, sendo que a maioria não conseguiu alcançar os objetivos definidos anteriormente. Outros tensionamentos, expostos pelos AIS/AISAN, foram: a sensação de estar só; a falta de interesse de alguns colegas de trabalho, adolescentes e jovens; além do próprio momento político que estavam vivenciando, marcado pela preparação para a Assembleia do Povo Xukuru e pelo movimento "Abril Indígena", que contou com a participação, em Brasília, dos jovens Xukuru mais ativos politicamente. Assim, a partir da necessidade de uma ação mobilizadora, diante do esvaziamento do grupo e de adequação da proposta à especificidade do contexto, iniciou-se o planejamento de uma Mostra de Saúde, a ser exposta na Assembleia, na qual AIS, AISAN e jovens indígenas desenvolveriam temas de interesse do povo.

Um dos objetivos da Mostra de Saúde seria estimular a formação dos grupos de adolescentes e jovens educadores em saúde. Após pactuação com integrantes do Conselho de Saúde e o de Lideranças, prosseguiu-se com o planejamento da divisão dos temas a serem desenvolvidos e a escolha da forma de apresentação (oficinas, barracas temáticas, exposição de vídeos). Alimentação saudável e reciclagem foram uns dos assuntos escolhidos para a exposição, sendo estes temas trabalhados com os agentes indígenas em um encontro antes da Mostra.

Na quarta reunião, foram realizadas: a oficina de reciclagem, que se constituiu num estímulo à produção de objetos com materiais normalmente não reutilizados, como plástico e papel; e a de alimentação saudável, onde AIS e AISAN elaboraram receitas à base de sementes, farinhas, folhas e partes de frutas e vegetais geralmente desprezadas. Diante da empolgação de alguns com o preparo diferenciado dos alimentos, foram escutadas frases como: "vou ter que comer isso mesmo?". Esta oficina tornou evidente que a cultura alimentar deste povo mostra-se semelhante à das populações não indígenas próximas, embora não se possa afirmar que seja inadequada ou menos saudável do que as preparações apresentadas.

No momento seguinte, deu-se a realização da Mostra de Saúde Xukuru, na Assembleia do Povo, realizada na aldeia Capim de Planta, em Pesqueira. O tema da assembleia problematizava a repercussão da criminalização das lideranças Xukuru, perseguidas e acusadas sem provas contundentes, o que centralizou esforços de articulação, especialmente na área jurídica, havendo grande concentração de gastos de recursos financeiros em pagamento de advogados. Desta forma, outras áreas de organização do povo, diante destes problemas, foram postas em outro nível de prioridade.

Ao todo, cinco temas foram desenvolvidos por adolescentes, jovens, AIS e AISAN, provenientes de nove aldeias. Os assuntos abordados foram: alimentação saudável, uso de plantas medicinais na cura tradicional, reciclagem, saúde bucal e história do povo. Aproximadamente quarenta adolescentes engajaram-se neste processo, preparando, eles mesmos, os produtos e materiais que seriam expostos 
EDUCAÇÃO POPULAR EM SAÚDE COM O POVO INDÍGENA ...

em suas bancas. O objetivo principal da Mostra era fortalecer o trabalho de formação dos grupos de agentes indígenas junto aos adolescentes e jovens, de forma a reconstruírem o papel e a imagem de educadores em saúde. Acordou-se, anteriormente à Mostra, que a exposição dos trabalhos seria feita nos intervalos da Assembleia, de forma a não promover um evento paralelo.

No final de cada dia da Mostra, uma roda de conversa com os adolescentes, AIS/AISAN e pesquisadores serviu como espaço de avaliação e criação de propostas para reformulação do trabalho para o dia seguinte. Ressaltou-se a importância de não apenas se apresentarem os materiais produzidos e vendê-los, nos casos das bancas de alimentação saudável e reciclagem, mas, também, provocar os visitantes à mudança de pequenos hábitos diários através de explicações e conversas.

Neste momento, adolescentes e jovens Xukuru exerceram seu perfil de liderança, ocupando um papel político nas discussões sobre saúde, sendo este um espaço até então vazio, com pouca intervenção tanto social quanto governamental. Por meio do estímulo à compreensão de responsabilidades mútuas dos jovens, AIS/AISAN e Funasa, buscou-se promover uma atuação transformadora do meio social a que estão integrados, fortalecendo a história e a identidade Xukuru.

\section{O momento pós-assembleia: ruídos de comunicação e pensamentos}

Após a assembleia, o cacique decidiu que a próxima oficina só aconteceria após uma reunião entre ele e os pesquisadores. Assim, por um período de quatro meses, aguardou-se a disponibilidade do líder. Entretanto, um encontro anterior foi solicitado por esta liderança com alguns AIS e pesquisadores de outros projetos do CPqAM. Por meio da análise do relatório desta reunião, observou-se que este momento foi conformado para levantamento de problemas do projeto de EPS, em especial, de fatos ocorridos na Mostra de Saúde.

Parte das críticas do cacique concentrou-se no fato de os produtos da oficina de reciclagem não terem passado pela sua avaliação. Para o líder, os produtos reciclados não estavam de acordo com o que ele concordava como produção de cultura Xukuru. Segundo o cacique, a introdução de técnicas de reciclagem foi uma ação cheia de boa vontade, mas falhou porque não considerou as reflexões do povo sobre a questão do lixo, assim como o processo de retomada das tradições e costumes. Quanto ao artesanato, o líder acredita que a produção de objetos com materiais recicláveis pode influenciar na perda do referencial cultural e étnico dos Xukuru.

A problemática da produção de objetos com materiais recicláveis traz, por um lado, uma preocupação legítima em relação à reinvenção da cultura do povo e permanência das tradições que, de acordo com as características indígenas, trazem elementos da natureza para a produção artesanal. Deste modo, a mercadoria cultural pode servir para fortalecer a expressão semiótica característica de uma sociedade, contribuindo com o fortalecimento da identidade Xukuru.

Críticas levantadas à gestão e assistência de saúde prestada pela Funasa também foram motivo de conflito com o cacique. Segundo ele, criou-se a impressão de que os Xukuru "são coniventes com os problemas e que não criticam o Subsistema". De fato, a Funasa assumia a atenção primária com limitações, em nível local, quanto ao quadro de profissionais para composição das equipes de saúde, à estrutura física dos postos e polos-base e à capacitação dos AIS/AISAN. Além disto, a articulação com os níveis de atenção à saúde secundária e terciária do SUS ocorria precariamente. Apesar destas dificuldades, na visão de alguns indígenas, os serviços de atenção primária geridos por este órgão sugerem uma condição especial, um status diferenciado ao atendimento.

De acordo com relatório da reunião citada anteriormente, em uma das falas, um AIS, voluntário do projeto de EPS, também membro do Conselho de Saúde Xukuru, procurou destacar que, desde a apresentação inicial da proposta, havia a preocupação de não se entrar em choque com as equipes de saúde nem com a organização e tradições do povo Xukuru. Segundo o AIS, a ideia do projeto era formar para a reflexão sobre a saúde e suas políticas e, para isto, a oficina de reciclagem foi pensada como uma estratégia para atrair os jovens. Ainda segundo o AIS, os Xukuru já exerciam uma reflexão crítica sobre o modelo de atenção curativo que a Funasa coordenava, mas, ao mesmo tempo, acreditavam que algumas questões precisavam ser mais bem aprofundadas. Em sua fala, também 
ressaltou a importância da continuidade do grupo de Educação Popular, mas expôs a necessidade de que os Xukuru tomem a decisão final frente às orientações e caminhos apontados.

A abordagem do tema da não-ingerência sobre os Xukurus traz à reflexão o que verdadeiramente foi colocado ou demandado sem acordo com os agentes indígenas e suas lideranças. Além disto, também sugere pensar se havia um fluxo saudável de comunicação entre os pesquisadores e os Xukuru, já que o preconizado pelo projeto de EPS era, justamente, a cocriação de uma maior autonomia daquele grupo. Desta forma, seria possível o questionamento de até onde os agentes sentiam-se à vontade para expor suas opiniões e, não havendo essa facilidade de diálogo, quais seriam os motivos que estariam levando a esta resistência. Apesar das questões levantadas, a iniciativa dos pesquisadores não pretendia impor decisões sobre as instituições governamentais ou sobre o povo, mas estimular uma visão problematizadora acerca do trabalho produzido pelos serviços de saúde, o que acabou sendo entendido como uma ameaça de estímulo à crítica da própria liderança Xukuru.

\section{Seminário final: a construção de um novo caminho para a educação em saúde}

No seminário final do projeto de educação popular em saúde - no qual estavam presentes lideranças, membros dos conselhos indígenas de saúde e de educação, agentes indígenas e pesquisadores -, o cacique Xukuru reiterou a importância do desenvolvimento das ações de educação em saúde com os AIS/AISAN. O reconhecimento, por parte do cacique, das limitações do papel destes profissionais - com a centralização do trabalho em visitas para marcar consultas e entregar medicamentos, o que, segundo ele, fortalecia apenas a "saúde curativa" - foi acompanhado de uma solicitação de continuidade do projeto de Educação em Saúde, com algumas modificações.

Para o líder, a proposta deveria ser reelaborada na forma de um curso de formação política para os agentes, que deveriam participar das reuniões não mais de forma voluntária. Também estabeleceu que houvesse a integração das ações com os professores e membros do Conselho de Educação.

O seminário final teve como encaminhamento a formação de um grupo de trabalho para elaborar o Plano de Formação para os AIS e AISAN, integrado com os calendários da Educação, Saúde e Funasa, de forma a evitar choques de atividades, encerrando-se, com este desfecho, a primeira etapa do projeto.

O novo curso de formação seria um caminho para promover educação e/em saúde, partindo de uma reflexão mais concreta sobre as políticas públicas e a organização do modelo de saúde do povo, de forma a estimular os agentes indígenas à compreensão do papel e da prática inerentes à sua função, diante das necessidades locais de intervenção, por meio do conhecimento dos processos de produção de saúde integral.

\section{Considerações finais}

O desenvolvimento da identidade de liderança entre os adolescentes e jovens Xukuru estaria vinculado à construção do protagonismo do AIS/AISAN que coordenaria o grupo local, devendo este estar aberto ao diálogo e à troca de saberes, e ter uma compreensão histórica do processo saúdedoença-saúde, agindo a partir da reflexão e da crítica. Entretanto, a qualidade de liderança de muitos agentes não se tinha desenvolvido, o que era perceptível pelas poucas falas durante as reuniões, pela timidez em colocar suas opiniões na roda, e, até mesmo, pela postura física cabisbaixa, sem coragem para fixar o olhar, ao comunicar-se.

A frequência mensal das reuniões entre AIS/AISAN e pesquisadores, para acompanhamento da prática educativa nas aldeias e para a realização das oficinas de formação em educação popular, representou um fator complicador para um coletivo que nunca vivenciou essa experiência, tornando-se insuficiente para a necessidade de apoio e orientação de que precisavam.

A operacionalização da metodologia de EPS proposta, baseada na formação de grupos de adolescentes e jovens, foi influenciada pela conjuntura social e pela organização espacial das aldeias, as quais se apresentam muito distantes entre si, sendo que a movimentação no território depende de transporte de carros de lotação ou motos, ainda escassos. 
EDUCAÇÃO POPULAR EM SAÚDE COM O POVO INDÍGENA ...

Um ponto bastante positivo a mencionar foi o reconhecimento, por parte das lideranças, da necessidade de formação política dos AIS e AISAN, o que se concretizou através do incentivo à criação de um novo projeto para estes profissionais.

\section{Colaboradores}

Os autores trabalharam juntos em todas as etapas de produção do manuscrito.

\section{Referências}

ALBUQUERQUE, P.C. A Educação Popular em Saúde no município de Recife-PE: em busca da integralidade. 2003. Tese (Doutorado) - Centro de Pesquisas Aggeu Magalhães, Fundação Oswaldo Cruz, Recife. 2003.

BRASIL. Ministério da Saúde. Descrição das competências profissionais do Agente Comunitário de Saúde. Brasília: MS, 2010. Disponível em: <http:// portal.saude.gov.br/portal/sgtes/visualizar_texto.cfm?idtxt=23095>. Acesso em: 18 abr. 2010.

BRITO, J.S.S. Educação popular em saúde com a comunidade indígena Xukuru do Ororubá, PE. 2010. Monografia (Residência em Saúde Coletiva) - Centro de Pesquisas Aggeu Magalhães, Fundação Oswaldo Cruz, Recife. 2010.

CARDOSO, E.J. Teoria da ação comunicativa de Habermas e suas implicações no processo educativo. Cesumar - Cienc. Hum. Soc. Aplic., v.9, n.2, p.29-37, 2004. Disponível em: <http://www.cesumar.br/pesquisa/periodicos/index.php/revcesumar/ article/view/237/932 > . Acesso em: 24 ago. 2012.

CECCIM, R.B. Pacientes impacientes: Paulo Freire. In: BRASIL. Secretaria de Gestão Estratégica e Participativa. Caderno de educação popular e saúde. Brasília: MS, 2007. p.32-45.

FREIRE, P. Educação e mudança. São Paulo: Paz e Terra, 2001.

FUNDAÇÃO NACIONAL DE SAÚDE. Manual de Atenção à Saúde da Criança Indígena Brasileira. Brasília: FUNASA, 2004.

PIANI, P.P.F. A organização sociopolítica do povo Xukuru. Disponível em: <http://www.eaesp.fgvsp.br/subportais/ceapg/Acervo\% 20Virtual/Cadernos/ Experi\% C3\% AAncias/2004/018organizacao_sociopolitica_do_povo_ xukuru_do_ororuba.pdf>. Acesso em: 16 dez. 2009.

SILVA, E.H. História, memórias e identidade entre os Xukuru do Ororubá. Rev. Tellus, v.7, n.12, p.89-102, 2007.

STOTZ, E.N.; DAVID, H.M.; BORNSTEIN, V.J. Educação Popular em Saúde. In: MARTINS, C.M.; STAUFFER, A.B. (Orgs.). Educação e saúde. Rio de Janeiro: EPSJV, Fiocruz, 2007. p.35-70.

THIOLLENT, M. Metodologia da pesquisa ação. 5.ed. São Paulo: Cortez, 1998.

VASCONCELOS, E.M. O Paulo da Educação Popular. In: BRASIL. Secretaria de Gestão Estratégica e Participativa. Caderno de educação popular e saúde. Brasília: MS, 2007. p.31. 
Este texto baseia-se em uma pesquisa-ação que analisa e reorienta as ações educativas em saúde realizadas pelos agentes indígenas de saúde (AIS) e agentes indígenas de saneamento (AISAN), no âmbito da atenção primária do povo Xukuru do Ororubá, no agreste pernambucano, Brasil. Propôs-se um trabalho que envolvesse tanto os agentes quanto a comunidade, para discutir as práticas de saúde, partindo dos referenciais teóricos da educação popular. O desenvolvimento das ações pedagógicas aconteceu por meio de oficinas e rodas de conversa. Estimulou-se a elaboração de atividades de promoção da saúde pelos AIS/AISAN a partir da constituição de grupos de adolescentes e jovens nas aldeias. Oficinas de formação de grupos, cidadania, reciclagem e alimentação saudável culminaram na "I Mostra de Saúde do Povo Xukuru". Limitações na operacionalização da metodologia proposta aconteceram durante o projeto, sobretudo devido à conjuntura política vivida pelo povo.

Palavras-chave: Educação em saúde. Saúde de populações indígenas.

\section{Popular health education with the Xukuru do Ororubá indigenous people}

This article is based on research that analyzed and reoriented health education actions undertaken by indigenous health agents (IHAs) and indigenous sanitary agents (ISAs) within primary care among the Xukuru do Ororubá people in the Agreste region of Pernambuco. The work proposed involved both the agents and the community, with the aim of discussing healthcare practices, building from theoretical reference points for popular education. Development of pedagogical actions took place through workshops and rounds of talks. The IHAs and ISAs were stimulated to draw up health promotion activities starting from formation of groups of teenagers and young people in the villages. The training workshops for groups, active citizenship, recycling and healthy eating culminated in the "First Healthcare Exhibition of the Xukuru People". There were some limitations on putting the proposed methodology into operation over the course of the project, mainly due to the political situation experienced by the Xukuru people.

Keywords: Health education. Health of indigenous peoples.

\section{Educación popular en salud con el pueblo indígena Xukuru de Ororubá, Brasil}

Este artículo está basado en una investigación-acción que analiza y re-orienta las acciones de educación en salud realizadas por los agentes de salud indígenas (AIS) y los agentes sanitarios indígenas (AISAN) en el ámbito de atención primaria del pueblo Xukuru de Ororubá en el área rural de Pernambuco Brasil. Se ha propuesto un trabajo que involucró los agentes y la comunidad, con el propósito de discutir las prácticas de salud, partiendo de las referencias teóricas de la educación popular. El desarrollo de acciones pedagógicas se produjo a través y "ruedas de conversación". Se estimuló el desarrollo de actividades de promoción de la salud por AIS/AISAN con la formación de grupos de adolescentes y jóvenes en las aldeas. Limitaciones en la aplicación práctica de la metodología propuesta fueron observadas durante el proyecto, principalmente debido a la situación política vivida por el pueblo.

Palabras clave: Educación en salud. Salud de poblaciones indígenas. 